\title{
“Association between Median Household Income, State Medicaid Expansion Status, and COVID-19 Outcomes Across US Counties"
}

Tsikata Apenyo (BS), Antonio Vera-Urbina, Khansa Ahmad (MD), Tracey H. Taveira (Pharm.D), WenChih Wu (MD/MPH)

Affiliations: The Providence Veterans Affairs Medical Center, Lifespan Hospitals and the Warren Alpert Medical School \& the School of Public Health at Brown University

\section{Address for correspondence:}

Wen-Chih $\mathrm{Wu}, \mathrm{MD}$.

Providence VA Medical Center

Miriam Hospital Cardiovascular Rehabilitation Center

Alpert Medical School and School of Public Health at Brown University

Division of Cardiology

830 Chalkstone Avenue

Providence, RI 02908

email: wen-chih.wu@va.gov

\section{Manuscript Word Count: 2445}




\section{Key Findings:}

Question: Is there a relationship between COVID-19 outcomes (incidence and mortality) and household income and status of Medicaid expansion of US counties?

Findings: In this longitudinal, retrospective analysis of 3142 US counties, we found no significant difference in COVID-19 incidence across US counties by quartiles of household income. However, counties with lower median household income had a higher risk of COVID-19 mortality, but only in nonMedicaid expansion states. This relationship was not significant in Medicaid expansion states.

Meaning: Expanded healthcare coverage through Medicaid expansion should be investigated as an avenue to attenuate the excessive COVID-19 mortality risk associated with low-income communities. 


\begin{abstract}
Objective: The relationship between socioeconomic status and its interaction with State's Medicaidexpansion policies on COVID-19 outcomes across United States (US) counties are uncertain. To determine the association between median-household-income and its interaction with State Medicaidexpansion status on COVID-19 incidence and mortality in US counties
\end{abstract}

Methods: Longitudinal, retrospective analysis of 3142 US counties (including District of Columbia) to study the relationship between County-level median-household-income (defined by US Census Bureau's Small-Area-Income-and-Poverty-Estimates) and COVID-19 incidence and mortality per 100000 of the population in US counties from January 20, 2020 through December 6, 2020. County median-householdincome was log-transformed and stratified by quartiles. Medicaid-expansion status was defined by US State's Medicaid-expansion adoption as of first reported US COVID-19 infection, January 20, 2020. Multilevel mixed-effects generalized-linear-model with negative binomial distribution and log link function compared quartiles of median-household-income and COVID-19 incidence and mortality, reported as incidence-risk-ratio (IRR) and mortality-risk-ratio (MRR), respectively. Models adjusted for county socio-demographic and comorbidity conditions, population density, and hospitals, with a random intercept for states. Multiplicative interaction tested for Medicaid-expansion*income quartiles on COVID-19 incidence and mortality.

Results: There was no significant difference in COVID-19 incidence across counties by income quartiles or by Medicaid expansion status. Conversely, significant differences exist between COVID-19 mortality by income quartiles and by Medicaid expansion status. The association between income quartiles and COVID-19 mortality was significant only in counties from non-Medicaid-expansion states but not significant in counties from Medicaid-expansion states ( $\mathrm{P}<0.01$ for interaction). For non-Medicaid- 
expansion states, counties in the lowest income quartile had a $41 \%$ increase in COVID-19 mortality compared to counties in the highest income quartile (MRR 1.41, 95\% CI: 1.25-1.59).

Conclusions and Relevance: Median-household-income was not related to COVID-19 incidence but negatively related to COVID-19 mortality in US counties of states without Medicaid-expansion. It was unrelated to COVID-19 mortality in counties of states that adopted Medicaid-expansion. These findings suggest that expanded healthcare coverage should be investigated further to attenuate the excessive COVID-19 mortality risk associated with low-income communities. 
medRxiv preprint doi: https://doi.org/10.1101/2021.02.03.21251075; this version posted February 5, 2021. The copyright holder for this preprint (which was not certified by peer review) is the author/funder, who has granted medRxiv a license to display the preprint in perpetuity.

It is made available under a CC-BY 4.0 International license .

\section{Background}

Instituted in the 1965, Medicaid has become the largest provider of health insurance in the United States (US) by providing medical access to people with low income and limited resources. ${ }^{1}$ The 2010 Affordable Care Act (ACA) sought to decrease the number of uninsured individuals by expanding Medicaid coverage and modifying individual insurance markets, ${ }^{2,3,4}$ but a 2012 Supreme Court decision overturned the requirement that states adopt Medicaid expansion. ${ }^{4,5}$ By January 2020, 14 states had yet to adopt Medicaid expansion. ${ }^{6}$ Studies have found that among states who implemented the ACA, the increased access to care has led to early diagnosis of cancers, diabetes, and depression among other health outcomes, ${ }^{7-10}$ but the relationship between Medicaid expansion and an infectious disease outbreak is unknown.

In 2019, a novel coronavirus (COVID-19), originating from Wuhan City, Hubei Province, China began spreading at an alarming rate. ${ }^{11}$ As COVID-19 progressed in the United States (US), the health toll disproportionally impacted African Americans and communities with high prevalence of poor housing conditions. ${ }^{12-14}$ In addition, COVID-19 has already been shown to impact individuals with certain preexisting health conditions at a greater rate. ${ }^{15}$ Both federal and state policymakers looked to Medicaid as a central tool in their response to the national emergency. ${ }^{16}$ However, whether differences exist in COVID19 outcomes between communities of Medicaid and non-Medicaid expansion states remains unknown. Moreover, it would be important to quantify differences in outcomes, if any, on the strata that appeared most impacted by COVID-19, the low-income communities, to help the states balance cost versus benefits. This is important because individuals without health insurance coverage are likely to be more vulnerable to the adverse health outcomes related to COVID-19. In the states that did not implement Medicaid expansion, 30 percent of low-income workers were uninsured before COVID-19. ${ }^{17}$ This number was less than half in Medicaid expansion states. ${ }^{17}$ 
medRxiv preprint doi: https://doi.org/10.1101/2021.02.03.21251075; this version posted February 5, 2021. The copyright holder for this preprint (which was not certified by peer review) is the author/funder, who has granted medRxiv a license to display the preprint in perpetuity.

It is made available under a CC-BY 4.0 International license .

We thereby sought to investigate the impact of COVID-19 in the counties nationwide according to their socio-economic status and investigate whether the impact varies by counties of states with Medicaid expansion versus those without Medicaid expansion. We stratified the US counties by its median household income and compared on their COVID-19 incident and mortality rates. We hypothesized that household income would be inversely related to COVID-19 incidence and mortality. Additionally, we hypothesize that a state's Medicaid expansion status will alter the association between median household income and COVID-19 outcomes.

\section{Methods}

We conducted a longitudinal, retrospective analysis of data of the US counties and District of Columbia $(\mathrm{n}=3142)$ using 2010-2019 baseline data from the Centers for Disease Control and Prevention and the US Census Bureau and related them to the COVID-19 outcome data from the John Hopkins Coronavirus Resource Center, 2020. ${ }^{18-21}$ Counties from US territories (American Samoa, Guam, Northern Mariana Island, Puerto Rico and US Virgin Islands, $n=105$ ) were not part of the analysis. ${ }^{18}$ All data used in this study were publicly available; therefore, the study met the criteria for exemption by the Providence Veterans Affairs Medical Center Institutional Review Board.

\section{$\underline{\text { Main Exposure Variables }}$}

Median household income for each county was collected from the 2018 US Census Bureau's Small Area Income and Poverty Estimates (SAIPE), ${ }^{19}$ and $\log$-transformed $(\ln \mathrm{X}+1)$ to approximate normality prior to stratification by quartiles. We defined Medicaid expansion states as those that had adopted expansion efforts as of the first case of COVID-19 in the United States on January 20, 2020 (Listing in Supplement). ${ }^{6}$ Counties in 36 states plus Washington, DC, were included in the Medicaid expansion group, while counties in 14 states were in the non-Medicaid expansion group. 
medRxiv preprint doi: https://doi.org/10.1101/2021.02.03.21251075; this version posted February 5, 2021. The copyright holder for this preprint (which was not certified by peer review) is the author/funder, who has granted medRxiv a license to display the preprint in perpetuity.

It is made available under a CC-BY 4.0 International license.

\section{$\underline{\text { Outcome }}$}

The main outcomes of our study were COVID-19 incidence and mortality per 100000 of the population. The absolute COVID-19 incidence and mortality rates of the US counties were obtained from the John Hopkins Coronavirus Resource Center and divided by the county population. Data from January 20, 2020 until December 6, 2020 were utilized for the analyses. ${ }^{21}$

\section{$\underline{\text { Covariates }}$}

Data on age and gender were collected using 2010 US Census Bureau data as the elderly and men have been reported as possessing a higher risk of COVID-19 mortality. ${ }^{19}$ The COVID-19 pandemic has been shown to afflict minority races in the US to a greater degree; therefore, we included data for racial composition of counties: percentage of White, Black, and Hispanic residents using US Census Bureau data from 2014-2018. Population density (population per square feet of land area) was calculated from the county population from 2010 US census divided by the square foot are of the county to account for overcrowding in a community. In addition to median-household income, we also abstracted data that were confirmatory of the socioeconomic status of the communities such as unemployment rate (2019), percentage of population age > 25 years without high school diploma (2014-2018), and percentage of population age $<65$ years without health insurance (2018). ${ }^{22}$ Access to care was assessed by number of hospitals per county (2017).

Since diabetes mellitus, obesity, and smoking are known risk factors for worse outcomes in COVID-19, ${ }^{23}$ we obtained the percentage of the population aged $>20$ years diagnosed with diabetes mellitus, with obesity, and percentage of adults who are current smokers from the Centers for Disease Control and Prevention from 2016-2018. ${ }^{20,23}$ 
medRxiv preprint doi: https://doi.org/10.1101/2021.02.03.21251075; this version posted February 5, 2021. The copyright holder for this preprint (which was not certified by peer review) is the author/funder, who has granted medRxiv a license to display the preprint in perpetuity.

It is made available under a CC-BY 4.0 International license .

\section{$\underline{\text { Statistical Analysis }}$}

Baseline characteristics for the counties were described by mean \pm standard deviation (SD) and range for continuous variables and percentage for categorical variables. Counties were stratified by quartiles of logtransformed median household income, which comprised of the following median household income ranges: Q1 (\$25385 - \$43681); Q2 (\$43688 - \$50565); Q3 (\$50568 - \$58838); Q4 (\$58848 - \$140382). Linear regression was used to test for trend of baseline characteristics across the income quartiles.

We used a multilevel mixed-effects generalized linear model with a negative binomial distribution and $\log$ link function to study the relationship between quartiles of log-median household income and COVID-19 outcomes across US counties: incidence and mortality, in a separate fashion, using Q4 as the referent. We applied a random intercept for states to account for clustering effect due to similarities in health policy for counties within the same state and specifying an unstructured covariance matrix. Using county population as the denominator in the model, the outcomes reported were incidence rate ratios (IRR) and mortality rate ratios (MRR) of COVID-19 across income quartiles of the counties, respectively. In a stepwise fashion, we first adjusted for demographics age over 65 years old, gender, and race (Model 1); followed by population density, diabetes, obesity, current smoking status, state Medicaid expansion status and number of hospitals (Model 2). The percentage of population without high school diploma under 25 years old and population without health insurance were not included in the model given their significant correlation with the median household income per county $(r=-0.36, P<0.001)$ and the Medicaid expansion status ( $r=-0.63, P<0.001)$ variables, respectively. We tested for interaction between quartiles of log-median household 'income quartile*Medicaid expansion status' on COVID-19 outcomes in Model 2. If the interaction proved to be significant, the above analyses were repeated stratified by counties of states with Medicaid Expansion $(n=1814)$ and counties of states without Medicaid Expansion $(n=1328)$. 
medRxiv preprint doi: https://doi.org/10.1101/2021.02.03.21251075; this version posted February 5, 2021. The copyright holder for this preprint (which was not certified by peer review) is the author/funder, who has granted medRxiv a license to display the preprint in perpetuity.

It is made available under a CC-BY 4.0 International license .

Sensitivity analyses were performed to replace median age in lieu of \% over 65 years old. All analyses were performed using STATA/SE version 11.2 software (StataCorp LP, College Station, TX). A 2-sided p-value of $<0.05$ was considered significant.

\section{Results}

As of December 6, 2020, there were a total of 14528356 COVID-19 cases, and 279115 COVID-19 deaths, across the 3142 counties. The mean (SD) for COVID-19 incidence and mortality were 5155.01 (4308.24) cases and 88.38 (96.46) deaths per 100000 population per county, respectively.

The characteristics of the 3142 counties, overall and stratified by four quartiles of log-transformed median household income are presented in Table 1. Overall, 57.7\% of counties were located in Medicaid expansion states. Higher median household income quartiles were associated with higher mean county population and population density, number of hospitals and percentage of white residents. Conversely, lower median household income quartiles were associated with higher percentage of elderly residents (65 years or older), black or Hispanic, unemployed and who did not have high school diploma or health insurance. Counties of lower income quartiles were also associated with a higher prevalence of diabetes, obesity and smoking and had a lower likelihood of belonging to a state that adopted Medicaid-expansion.

The mean number of COVID-19 cases and deaths per 100000 population across counties from different income quartiles were described in Table 2. There was no significant association between COVID-19 incidence and quartiles of household income in unadjusted and demographic adjusted analyses. In the fully adjusted model, counties from income quartile 2 had a $10 \%$ increase in the risk of COVID-19 incidence compared to quartile 4 (IRR 1.10, 95\% CI: 1.04-1.17). The interaction 'income quartile*Medicaid expansion status' was not significant for COVID-19 incidence (P values 0.07 to 0.20 Q1-3). 
medRxiv preprint doi: https://doi.org/10.1101/2021.02.03.21251075; this version posted February 5, 2021. The copyright holder for this preprint (which was not certified by peer review) is the author/funder, who has granted medRxiv a license to display the preprint in perpetuity.

It is made available under a CC-BY 4.0 International license .

Conversely, there was a significant association between COVID-19 mortality and quartiles of household income. In the fully adjusted model, counties from income quartile 1 had a $22 \%$ increase in the risk of COVID-19 mortality compared to quartile 4 (MRR 1.22, 95\% CI 1.09-1.35). Furthermore, the interaction 'income quartile*Medicaid expansion status’ was significant (P values $<0.01, \mathrm{Q} 1-3$ ), for which subgroup analyses by Medicaid expansion status were conducted. The sensitivity analyses replacing \% population over 65 years old with median age of the county population did not significantly change the results.

The comparison of baseline characteristics between counties in Medicaid and non-Medicaid expansion states were described in Table 3. Counties from states with Medicaid expansion had a higher population density, percentage of white residents, median household income, unemployment rate, number of hospitals; and a lower percentage of population who were Black, Hispanic, without high school diploma, without health insurance, with diabetes, with obesity or reported being a current smoker. The association between household income quartiles and COVID-19 mortality by state Medicaid expansion status was depicted in Figure 1 and described in supplemental Table 2. In fully adjusted analyses, median household income quartiles were associated with COVID-19 mortality only in counties within states without adoption of Medicaid expansion, such that counties in the lowest income quartile had a $41 \%$ increase in COVID-19 mortality compared to counties in the highest income quartile (MRR 1.41, 95\% CI: 1.25 1.59). Contrarily, income quartiles were not associated with COVID-19 mortality in counties within states that adopted Medicaid expansion.

\section{Discussion}

To our knowledge, this is the first paper to study the association of median household income with COVID-19 outcomes at the county level, in Medicaid expansion and non-expansion states. We found no significant difference in COVID-19 incidence across counties by income quartiles or by Medicaidexpansion status. However, significant differences exist between COVID-19 mortality by income quartiles and by Medicaid-expansion status, such that the association between income quartiles and 
COVID-19 mortality was significant only in counties from non-Medicaid-expansion states but not significant in counties from Medicaid-expansion states.

There is ample evidence to support that socioeconomic status is related to health outcomes. Ahmad et al. showed that the percentage of population living in poverty in communities was associated with a higher cardiovascular and heart failure mortality. ${ }^{24}$ Same investigators have also shown that counties with higher percentage of households living in poor housing conditions had significantly higher risk of COVID-19 incidence and mortality. ${ }^{14}$ In this study, we showed that COVID-19 infection affected communities of distinct income strata in a similar fashion, but with a higher mortality risk in communities of lower household income. Multiple mechanisms have been posited to explain poor health outcomes in lowincome population. It is possible that people in lower-income communities have worse health at baseline, receive care at lower quality hospitals, receive differential care within a hospital due to lack of health insurance or poor health literacy, and/or there is a lack of access to care outside of the hospital due to lack of health insurance. ${ }^{25,26}$ We found higher prevalence of obesity, diabetes and smoking in lower income communities to support some of these mechanisms. Moreover, the findings of low-income communities associated with higher COVID-19 mortality risk in non-Medicaid expansion states but no relationship in Medicaid expansion states, strongly suggest that access to health care and health insurance is a potential modifiable risk factor for health disparity in COVID-19 mortality.

Over the past decade, studies have shown that in the states that expanded Medicaid coverage, there were improvements in diagnosis, management and mortality of chronic conditions..$^{7-10,27-29}$ Further studies have also investigated the impact on disease mortality rates in Medicaid expansion states on a nationwide scale. ${ }^{30,31}$ In end-stage renal disease, patients had improved 1-year survival rates in Medicaid expansion states. ${ }^{31}$ Similarly, a decrease in cardiovascular mortality was observed in states after Medicaid expansion. This was considered to be a benefit of improved access to healthcare. ${ }^{30}$ We believe a similar mechanism is at play when it comes to COVID-19 mortality. As shown in our study, in non-Medicaid 
expansion states, we observed a significant negative association between median household income and COVID-19 mortality which was not seen in Medicaid expansion states. This is likely explained by the improved access to healthcare offered by the ACA which increased access to healthcare insurance of low income individuals by raising the Medicaid eligibility threshold to $138 \%$ of the federal poverty level. ${ }^{32} \mathrm{~A}$ review of literature shows that individuals without health insurance are less likely to seek health care even when in need. ${ }^{33}$ In contrast it has been shown that when they could afford care, individuals were more likely to utilize healthcare resources. ${ }^{34}$ Therefore, while a proportion of population in high income communities are able to afford insurance regardless of state expansion status, we offered evidence that access to health care through Medicaid expansion likely helped close the coverage disparity for lowincome individuals in low-income communities from Medicaid expansion states. These results can have policy implications. We posit that improved access to healthcare insurance such as Medicaid expansion could lead to lower uninsured rates among low-income individuals, improving access to healthcare, thereby lowering the adverse impact of COVID-19 in low-income communities. ${ }^{23,35,36}$

\section{$\underline{\text { Limitations and Strengths }}$}

This is a nationwide study, that utilized representative data of US communities suitable to assess outcomes as it relates to policy. Study limitations include its observational design, inability to conclude causality and the potential for residual confounding despite our careful control of known confounders. Although some states adopted Medicaid expansion into their state constitution during 2020 (Missouri and Oklahoma), none of them achieved implementation stage during 2020.

\section{Conclusions and Implications}

Median-household-income was not related to COVID-19 incidence but negatively related to COVID-19 mortality in US counties of states without Medicaid-expansion. It was unrelated to mortality in counties of states that adopted Medicaid-expansion. These findings suggest expanded health coverage should be 
medRxiv preprint doi: https://doi.org/10.1101/2021.02.03.21251075; this version posted February 5, 2021. The copyright holder for this preprint (which was not certified by peer review) is the author/funder, who has granted medRxiv a license to display the preprint in perpetuity.

It is made available under a CC-BY 4.0 International license.

investigated further to attenuate the excessive COVID-19 mortality risk associated with socioeconomically disadvantaged communities.

\section{ACKNOWLEDGEMENT}

The views expressed in this paper represent the authors and not the Department of the Veterans Affairs.

\section{DISCLOSURES}

None 
medRxiv preprint doi: https://doi.org/10.1101/2021.02.03.21251075; this version posted February 5, 2021. The copyright holder for this preprint (which was not certified by peer review) is the author/funder, who has granted medRxiv a license to display the preprint in perpetuity.

It is made available under a CC-BY 4.0 International license .

\section{$\underline{\text { References }}$}

1. Iglehart JK, Sommers BD. Medicaid at 50 - From Welfare Program to Nation's Largest Health Insurer. N Engl J Med. 2015;372(22):2152-2159.

2. McMorrow S, Blumberg LJ, Holahan J. Ten Years Later: Reflections on Critics' WorstCase Scenarios for the Affordable Care Act. J Health Polit Policy Law. 2020;45(4):465483.

3. Michener J. Race, Politics, and the Affordable Care Act. J Health Polit Policy Law. 2020;45(4):547-566.

4. Mazurenko O, Balio CP, Agarwal R, Carroll AE, Menachemi N. The Effects Of Medicaid Expansion Under The ACA: A Systematic Review. Health Affairs. 2018;37(6):944-950.

5. Aug P. A Guide to the Supreme Court's Decision on the ACA's Medicaid Expansion. In. KFF2012.

6. Status of State Action on the Medicaid Expansion Decision. In. KFF2020.

7. Carey C, Miller S, Wherry L. The Impact of Insurance Expansions on the Already Insured: The Affordable Care Act and Medicare. Cambridge, MA: National Bureau of Economic Research; 2018/10// 2018. w25153.

8. Cha P, Brindis CD. Early Affordable Care Act Medicaid: Coverage Effects for Low- and Moderate-Income Young Adults. Journal of Adolescent Health. 2020.

9. Chen J, Vargas-Bustamante A, Mortensen K, Ortega AN. Racial and Ethnic Disparities in Health Care Access and Utilization Under the Affordable Care Act. Med Care. 2016;54(2):140-146.

10. McMorrow S, Long SK, Kenney GM, Anderson N. Uninsurance Disparities Have Narrowed For Black And Hispanic Adults Under The Affordable Care Act. Health Affairs. 2015;34(10):1774-1778.

11. Wu Y-C, Chen C-S, Chan Y-J. The outbreak of COVID-19: An overview. Journal of the Chinese Medical Association. 2020;83(3):217-220.

12. Finch WH, Hernández Finch ME. Poverty and Covid-19: Rates of Incidence and Deaths in the United States During the First 10 Weeks of the Pandemic. Front Sociol. 2020;5.

13. Ferdinand KC, Nasser SA. African-American COVID-19 Mortality. Journal of the American College of Cardiology. 2020;75(21):2746-2748.

14. Ahmad K, Erqou S, Shah N, et al. Association of poor housing conditions with COVID19 incidence and mortality across US counties. PLOS ONE. 2020;15(11):e0241327.

15. Laires PA, Nunes C. Population-based Estimates for High Risk of Severe COVID-19 Disease due to Age and Underlying Health Conditions. Acta Med Port. 2020.

16. Schubel J. States Are Leveraging Medicaid to Respond to COVID-19.14.

17. Cross-Call J, Broaddus M. States That Have Expanded Medicaid Are Better Positioned to Address COVID-19 and Recession.18.

18. Bureau USC. Geographic Areas Reference Manual. The United States Census Bureau.

19. SAIPE.

20. Interactive Atlas of Heart Disease and Stroke Tables.

21. COVID-19 United States Cases by County. Johns Hopkins Coronavirus Resource Center.

22. Bureau USC. 2008 - 2018 SAHIE using the American Community Survey (ACS). The United States Census Bureau.

23. Cdc. COVID-19 and Your Health. Centers for Disease Control and Prevention. 2020. 
medRxiv preprint doi: https://doi.org/10.1101/2021.02.03.21251075; this version posted February 5, 2021. The copyright holder for this preprint (which was not certified by peer review) is the author/funder, who has granted medRxiv a license to display the preprint in perpetuity.

It is made available under a CC-BY 4.0 International license .

24. Ahmad K, Chen EW, Nazir U, et al. Regional Variation in the Association of Poverty and Heart Failure Mortality in the 3135 Counties of the United States. J Am Heart Assoc. 2019;8(18).

25. Committee on Accounting for Socioeconomic Status in Medicare Payment P, Board on Population H, Public Health P, et al. Accounting for Social Risk Factors in Medicare Payment: Data. Washington (DC): National Academies Press (US); 2016.

26. Joynt Karen E, Zuckerman R, Epstein Arnold M. Social Risk Factors and Performance Under Medicare's Value-Based Purchasing Programs. Circulation: Cardiovascular Quality and Outcomes. 2017;10(5):e003587.

27. Eliason EL. Adoption of Medicaid Expansion Is Associated with Lower Maternal Mortality. Women's Health Issues. 2020;30(3):147-152.

28. Rosenberg K. Medicaid Expansion Leads to Improved Breast Cancer Care. Journal of Nursing. 2018;118(5).

29. Kim U, Koroukian S, Statler A, Rose J. The effect of Medicaid expansion among adults from low-income communities on stage at diagnosis in those with screening-amenable cancers. Cancer.n/a(n/a).

30. Khatana SAM, Bhatla A, Nathan AS, et al. Association of Medicaid Expansion With Cardiovascular Mortality. JAMA Cardiol. 2019;4(7):671.

31. Swaminathan S, Sommers BD, Thorsness R, Mehrotra R, Lee Y, Trivedi AN. Association of Medicaid Expansion With 1-Year Mortality Among Patients With EndStage Renal Disease. JAMA. 2018;320(21):2242.

32. Mistry JB, Gwam C, Delanois RE. Medicaid and state-based programs. Seminars in Arthroplasty. 2016;27(3):196-200.

33. Taber JM, Leyva B, Persoskie A. Why do People Avoid Medical Care? A Qualitative Study Using National Data. J Gen Intern Med. 2015;30(3):290-297.

34. Singh KA, Wilk AS. Affordable Care Act Medicaid Expansion and Racial and Ethnic Disparities in Access to Primary Care. Journal of Health Care for the Poor and Underserved. 2019;30(4):1543-1559.

35. Present MA, Nathan AG, Ham SA, et al. The Impact of the Affordable Care Act Medicaid Expansion on Type 2 Diabetes Diagnosis and Treatment: A National Survey of Physicians. J Community Health. 2019;44(3):463-472.

36. Huguet N, Springer R, Marino M, et al. The impact of the Affordable Care Act Medicaid expansion on visit rates for a patient population with diabetes or pre-diabetes in safety net health centers. J Am Board Fam Med. 2018;31(6):905-916. 


\section{Log Transformed Median Household Income Quartiles}

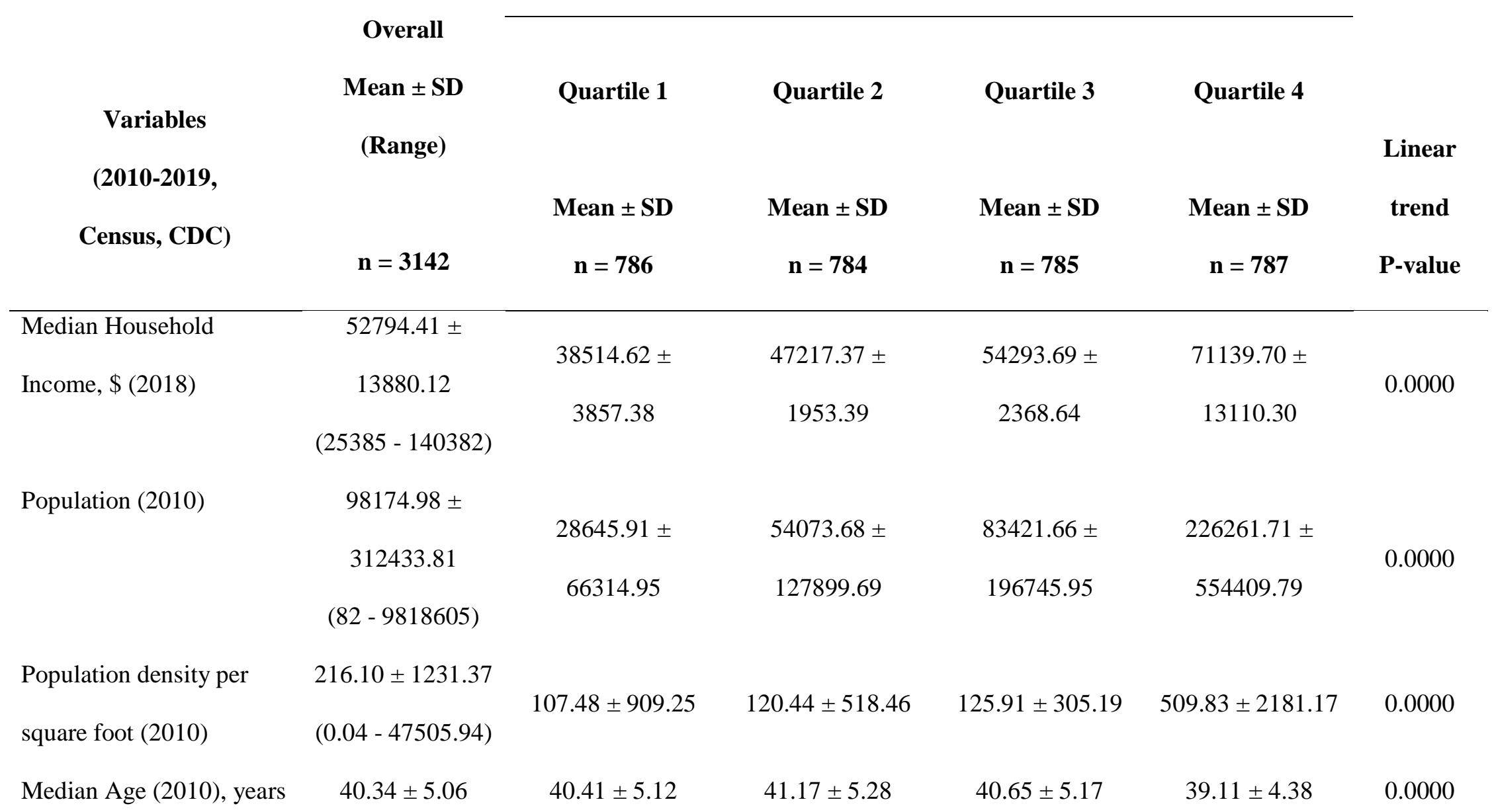


Population $>65$ years

(2010), \%

Male (2010), \%

White (2014-2018), \%

$$
\text { Black (2014-2018), \% }
$$$$
\text { White (2014-2018), \% }
$$

Hispanic Latino

(2014-2018), \%

Unemployment rate

(2019), \%

Age $>25$ years without

high school diploma,

(2014-2018), \%

Age $<65$ years without

insurance (2018), \%
$15.88 \pm 4.19$

$(3.47-43.38)$

$49.98 \pm 2.22$

(43.20 - 72.10)

$$
49.98 \pm 2.95
$$

$50.11 \pm 2.31$

$49.90 \pm 1.58$

$49.91 \pm 1.79$

0.2134

$$
76.45 \pm 20.18
$$

$$
\text { (0.7 - 100) }
$$

$$
67.03 \pm 24.87
$$

$79.91 \pm 17.72$

$81.26 \pm 16.29$

$77.60 \pm 17.55$

0.0000

$$
\begin{gathered}
8.87 \pm 14.46 \\
(0-87.4)
\end{gathered}
$$

$17.86 \pm 21.53$

$7.04 \pm 11.23$

$4.99 \pm 8.37$

$5.60 \pm 8.23$

0.0000

$9.21 \pm 13.79$

(0 - 99)

$4.00 \pm 1.48$

$(0.7-19.3)$

$4.93 \pm 1.71$

$4.10 \pm 1.40$

$3.69 \pm 1.16$

$3.28 \pm 1.05$

0.0000

$13.41 \pm 6.34$

$(1.2-66.3)$

$19.22 \pm 6.03$

$13.60 \pm 5.08$

$11.50 \pm 4.95$

$9.31 \pm 4.45$

0.0000

$11.50 \pm 5.04$

(2.4 - 32.2)
$14.00 \pm 4.89$

$12.37 \pm 4.86$

$10.53 \pm 4.67$

$9.11 \pm 4.31$

0.0000 
Number of Hospitals per

county (2017)

Age $\square$ adjusted population

with diabetes mellitus,

age $>20$ years $(2016), \%$

Age $\square$ adjusted population

with obesity, age $>20$

years (2016), \%

Population with reported

smoking (2017), \%

Number of Counties in

states with Medicaid

1814

$$
\begin{gathered}
1.46 \pm 2.56 \\
(0-79)
\end{gathered}
$$

$10.38 \pm 3.80$

$(1.5-33)$

$32.76 \pm 5.70$

(12.3 - 57.9)

$17.47 \pm 3.63$

$(6-41)$

$20.58 \pm 3.82$

$17.93 \pm 2.79$

$16.46 \pm 2.51$

$14.89 \pm 2.53$

0.0000

expansion
321
514

562

N/A

Table 2: Association of SARS-COV-2 outcomes as of December 6, 2020 with Median Household Income Quartiles 


\begin{tabular}{|c|c|c|c|c|}
\hline \multirow[b]{2}{*}{ SARS-CoV2 Outcomes } & \multicolumn{4}{|c|}{ Median Household Income Quartiles } \\
\hline & Quartile 1 & Quartile 2 & Quartile 3 & Quartile 4 \\
\hline \multirow[t]{3}{*}{ (As of December 6, 2020) } & $\mathrm{N}=786$ & $\mathrm{~N}=784$ & $\mathrm{~N}=785$ & $\mathrm{~N}=787$ \\
\hline & IRR / MRR & IRR / MRR & IRR / MRR & IRR / MRR \\
\hline & $(95 \% \mathrm{CI})$ & $(95 \% \mathrm{CI})$ & $(95 \% \mathrm{CI})$ & $(95 \% \mathrm{CI})$ \\
\hline $\begin{array}{l}\text { Cases per } 100,000 \text { population } \\
\qquad(\text { mean } \pm S D)\end{array}$ & $5121.08 \pm 2471.59$ & $5299.32 \pm 5338.71$ & $5166.40 \pm 2666.65$ & $5033.77 \pm 5705.18$ \\
\hline \multirow[t]{2}{*}{ Model 1} & 0.96 & 1.05 & 0.96 & REFERENT \\
\hline & {$[0.90-1.02]$} & {$[0.99-1.10]$} & {$[0.91-1.01]$} & \\
\hline \multirow[t]{2}{*}{ Model 2* } & 1.04 & 1.10 & 1.00 & REFERENT \\
\hline & {$[0.97-1.12]$} & [1.04-1.17] & {$[0.95-1.05]$} & \\
\hline $\begin{array}{l}\text { Deaths per } 100,000 \text { population } \\
\qquad(\text { mean } \pm S D)\end{array}$ & $113.32 \pm 87.43$ & $92.21 \pm 109.58$ & $75.69 \pm 62.84$ & $72.32 \pm 112.19$ \\
\hline \multirow[t]{2}{*}{ Model 1} & 1.16 & 1.15 & 0.99 & REFERENT \\
\hline & {$[1.06-1.26]$} & [1.07-1.24] & [0.93-1.06] & \\
\hline \multirow[t]{2}{*}{ Model 2* } & 1.22 & 1.18 & 1.02 & REFERENT \\
\hline & {$[1.09-1.35]$} & {$[1.08-1.28]$} & {$[0.95-1.10]$} & \\
\hline
\end{tabular}

IRR = Incident Rate Ratio $;$ MRR = Mortality Rate Ratio $; 95 \%$ CI = 95\% Confidence Interval 
Model 1: \% Population > 65 years, $\%$ Male, and $\%$ White

Model 2: \% Population > 65 years, \% Male, \% White, Population Density, \% Obesity, \% Smoking, \% Diabetes, Number

of Hospitals, Medicaid expansion status according to state policy

*Interaction between income quartiles and Medicaid status was significant (p-value $\leq 0.005$ ) for SARS-COV-2 mortality

but not for SARS-CoV2 Cases (p-value $\geq 0.073$ )

\#Differences between means were statistically significant (p-value < 0.0000) for SARS-COV-2 Deaths per 100,000

population but not for SARS-COV-2 Cases per 100,000 population ( $\mathrm{p}$-value $<0.6693$ ) 
Table 3: Counties Baseline Characteristics by Medicaid Expansion Status of the State

\section{Variables}

(2010-2020, Census, CDC, Johns Hopkins

Coronavirus Resource Center)

Population (2010)

Population density per square foot (2010)

Median Age (2010), years

Population > 65 years $(2010), \%$

Male (2010), \%

White (2014-2018), \%

Black (2014-2018), \%

Hispanic Latino (2014-2018), \%

Overall, Median Household Income (2018), \$

Quartile 1, Median Household Income (2018), \$

Quartile 2, Median Household Income (2018), \$

\section{Counties within States with Counties within States without}

Medicaid Expansion

$\mathbf{n}=\mathbf{1 8 1 4}$

Mean \pm SD

\section{Medicaid Expansion}

$\mathbf{n}=\mathbf{1 3 2 8}$

Mean \pm SD
P-value

$76354.07 \pm 212778.78$

$115.30 \pm 275.52$

$39.77 \pm 4.94$

$15.79 \pm 4.25$

$49.90 \pm 2.41$

$70.33 \pm 21.23$

$13.28 \pm 17.56$

$11.38 \pm 16.48$

$49084.12 \pm 11411.09$

$38550.68 \pm 3800.93$

$46990.50 \pm 1944.14$
0.0008

0.0001

0.0000

0.3138

0.1078

0.0000

0.0000

0.0000

0.0000

0.7526

0.0022 
Quartile 3, Median Household Income (2018), \$

Quartile 4, Median Household Income (2018), \$

Unemployment rate (2019), \%

Population without high school diploma, aged

$>25$ years (2014-2018), \%

Population without health insurance, aged $<65$

years (2018), \%

Number of Hospitals per county (2017)

Age $\square$ adjusted population with diabetes mellitus,

aged $>20$ years $(2016), \%$

Age $\square$ adjusted population with obesity, aged $>20$

years (2016), \%

Population with reported smoking (2017), \%

Cases per 100,000 population

(As of December 6, 2020)

Deaths per 100,000 population

(As of December 6, 2020)

$$
4.13 \pm 1.63
$$

$11.80 \pm 5.54$

$$
8.77 \pm 3.26
$$

$$
1.58 \pm 2.96
$$

$9.70 \pm 3.38$

$$
32.12 \pm 5.70
$$

$17.09 \pm 3.63$

$4944.19 \pm 17503.34$

$105.65 \pm 453.88$
$4186.45 \pm 12891.29$

0.1821

\section{$54213.89 \pm 2465.68$ \\ $68089.64 \pm 9787.66$

$$
3.81 \pm 1.24
$$

$15.61 \pm 6.69$

0.0000

0.0000

0.0010

0.0000

$11.30 \pm 4.14$

0.0000

$17.98 \pm 3.39$

0.0000

$65.86 \pm 202.01$

0.0028 


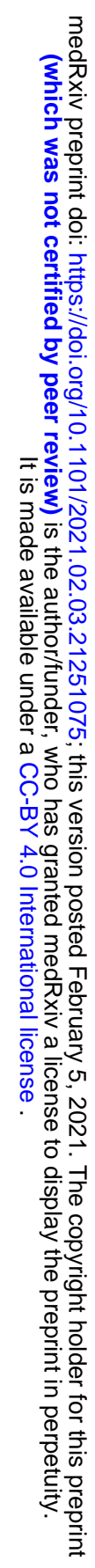


Figure 1. Association of SARS-COV-2 Mortality Rate Ratios by Median Household Income Quartiles, for counties in Medicaid and Non-Medicaid expansion states, referent $=$ Quartile 4

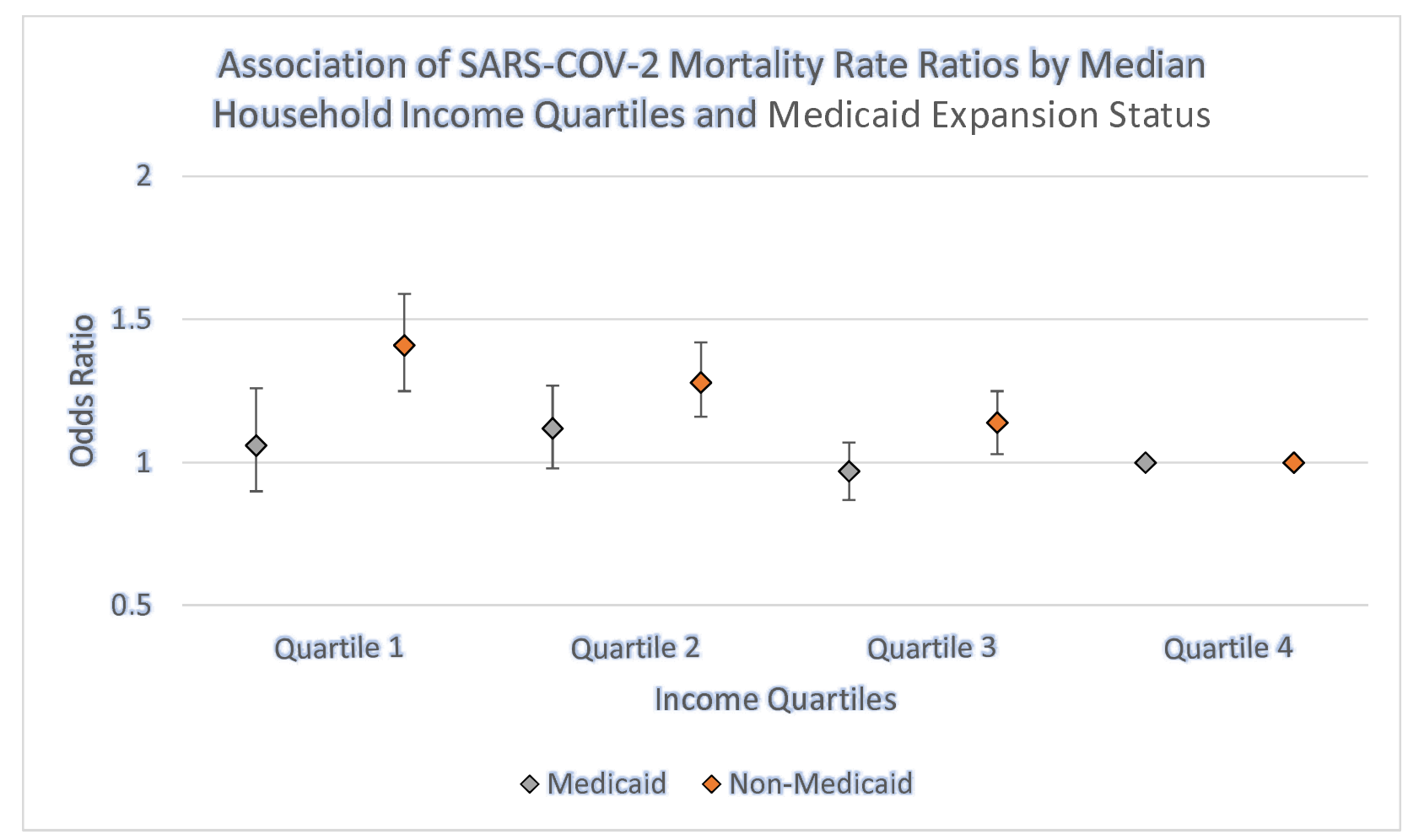

